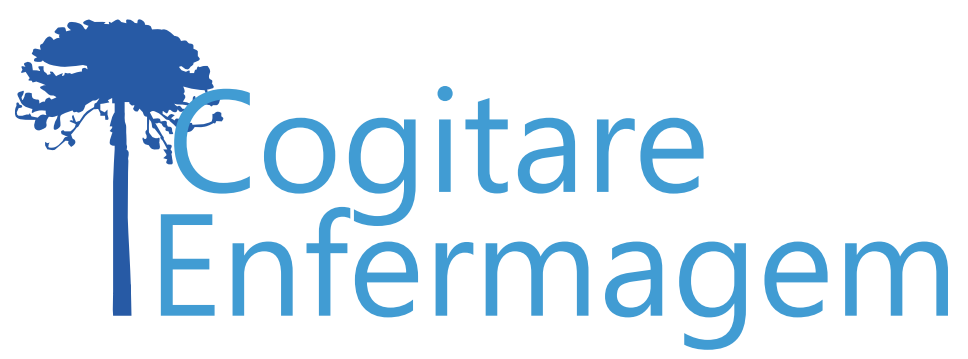

REVISÃO

\title{
USO DAS TEORIAS DE ENFERMAGEM NAS TESES BRASILEIRAS: ESTUDO BIBLIOMÉTRICO
}

\author{
Héryka Laura Calú Alves ${ }^{1}$ (i) \\ Gabriela de Sousa Lima ${ }^{1}$ (i) \\ Grayce Alencar Albuquerque ${ }^{1}$ (1) \\ Emiliana Bezerra Gomes ${ }^{1}$ (1) \\ Edilma Gomes Rocha Cavalcante ${ }^{1}$ (i) \\ Maria Corina Amaral Viana' ${ }^{1}$ (])
}

\section{RESUMO}

Objetivo: caracterizar a produção científica que utiliza teorias de enfermagem a partir de teses realizadas por enfermeiros no Brasil.

Método: estudo bibliométrico realizado no Banco de Teses da Coordenação de Aperfeiçoamento Pessoal de Nível Superior e na Plataforma Sucupira, em novembro de 2019. Foram selecionadas 63 teses lidas na íntegra para fichamento e extração de aspectos de interesse, a seguir: ano, universidade, autor, orientador, programa, teoria, modo de aplicação, tipo de estudo, natureza e temática.

Resultados: o maior número de produções aconteceu em 2016 com 16 (25,4\%) teses, com destaque para o Nordeste com 31 (49,2\%). A teoria mais utilizada foi a Teoria do Cuidado Transcultural em oito (12,7\%), com a temática mais investigada sendo o cuidado em 12 (13\%) teses.

Conclusão: a inclusão das teorias de enfermagem no ensino e na pesquisa ainda se mantêm obscuras. Pretende-se dar visibilidade à temática e sugerir o aprofundamento na discussão.

DESCRITORES: Teoria de Enfermagem; Pesquisa em Enfermagem; Bibliometria; Enfermagem; Saúde.

\section{USO DE LAS TEORÍAS DE ENFERMERÍA EN LAS TESIS BRASILEÑAS: ESTUDIO BIBLIOGRÁFICO}

\section{RESUMEN:}

Objetivo: caracterizar la producción científica que utiliza las teorías de enfermería basadas en las tesis hechas por enfermeras en Brasil. Método: estudio bibliométrico realizado en el Banco de Tesis de Banco de Teses da Coordenação de Aperfeiçoamento Pessoal de Nível Superior y en la Plataforma Sucupira, en noviembre de 2019. Se seleccionaron 63 tesis leídas en su totalidad para fichas y extracción de aspectos de interés, como sigue: año, universidad, autor, orientador, programa, teoría, modo de aplicación, tipo de estudio, naturaleza y tema. Resultados: el mayor número de producciones se produjo en 2016 con 16 (25,4\%) tesis, destacándose el Nordeste con 31 (49,2\%). La teoría más utilizada fue la Teoría de los Cuidados Transculturales en ocho (12,7\%), siendo el tema más investigado el de los cuidados en 12 (13\%) tesis. Conclusión: la inclusión de las teorías de enfermería en la enseñanza y la investigación sigue siendo oscura. La intención es dar visibilidad al tema y sugerir la profundización de la discusión. DESCRIPTORES: Teoría de Enfermería; Investigación en Enfermería; Bibliometría; Enfermería; Salud. 
Definido por muito tempo como o profissional do "fazer", dissociado do conhecimento científico, o enfermeiro teve sua construção identitária influenciada por nuances históricas, sociais e conceituais, em um contexto em que o desenvolvimento do mercado de trabalho, a introdução de tecnologias e a globalização do saber e fazer, toma força na determinação de papéis e na promoção da assistência à saúde ${ }^{(1)}$.

O início da cientifização da enfermagem se deu a partir dos conceitos nightingaleanos, que utilizando de um método científico, a observação, passou a redigir os primeiros escritos científicos da enfermagem, que tem como seu grande paradigma o cuidado, discutido e construído como objeto da profissão(2).

No contexto atual, a afirmação da enfermagem enquanto profissão com campo próprio do saber requer dos enfermeiros a condução das suas práticas com base no saber científico, ação respaldada nas diversas organizações governamentais e da categoria ao redor do mundo, que preconizam a necessidade de profissionais capazes, por meio da ciência, de diagnosticar, adotar medidas preventivas, curativas, reabilitadoras e promotoras da saúde na população ${ }^{(3)}$. Uma parte própria dessa ciência são as teorias, que fornecem material teórico e prático ao ser enfermeiro.

As teorias consistem em conjuntos de conceitos que transmitem o olhar sistêmico sobre um fenômeno. Demonstram ser úteis na descrição, explicação e prescrição de medidas na prática assistencial, ou seja, respaldam os saberes e práticas da enfermagem. Assim, a construção e validação de teorias pela pesquisa são necessárias para o avanço da enfermagem enquanto profissão e ciência ${ }^{(4)}$.

A enfermagem é detentora de um processo de cuidar dinâmico, sistematizado e cientificamente embasado, e com suas teorias é capaz de relacionar os fatos e formar a base científica para atuação profissional, colocando o indivíduo dentro de um contexto que recebe influências sociais, ambientais e humanas ${ }^{(3)}$. Para a solidificação desse conhecimento produzido, a enfermagem vai se reformulando continuamente e refinando conceitos e teorias, que estão intimamente ligados à evolução e expansão da profissão(4).

Com isso, a pesquisa em enfermagem surge como fio condutor para a melhoria do cuidado e ampliação de ações e estratégias para seu gerenciamento, fundamentadas em teorias próprias, voltadas à interação humanizada entre a equipe de enfermeiros e o paciente ${ }^{(5)}$.

No contexto dos cursos de pós-graduação, a produção do conhecimento e aplicação das teorias de enfermagem vêm fundamentando e fortalecendo a ciência, a tecnologia e a inovação da profissão. Tal fortalecimento está associado à produção de pesquisas dos cursos stricto sensu, mestrados e doutorados em enfermagem no Brasil e no mundo, e na qualidade, divulgação e aplicabilidade das suas produções e publicações ${ }^{(6)}$.

O doutoramento, que tem como nível preliminar de acesso o mestrado, é uma prioridade da área, tendo sua qualidade reconhecida por meio da inserção dos doutores no mercado de trabalho com indicadores positivos relacionados à pesquisa com financiamento e cargos relevantes no serviço e na academia ${ }^{(6)}$. É dos programas de pós-graduação das universidades que advém o maior número de produções com teorias de enfermagem ${ }^{(5)}$.

Entende-se, portanto, que as teorias são a base de uma enfermagem pautada na cientificidade; então, se faz importante conhecer como os enfermeiros as utilizam em suas pesquisas de doutorado. Para tanto, esse estudo objetivou caracterizar a produção científica que utiliza teorias de enfermagem a partir de teses realizadas por enfermeiros no Brasil. 
Trata-se de uma revisão bibliométrica, de caráter descritivo e abordagem quantitativa, que versa sobre avaliação do desenvolvimento e crescimento de produções científiças em determinadas áreas presentes na literatura, a partir de métodos quantitativos ${ }^{(7)}$. É fruto da disciplina de Bases Teóricas e Conceituais do Cuidado de Enfermagem, cursada no Mestrado Acadêmico em Enfermagem da Universidade Regional do Cariri.

O estudo foi realizado em novembro de 2019, e seu percurso metodológico ocorreu por meio de elaboração empírica da temática, utilização de protocolo de pesquisa criado pelas próprias pesquisadoras para orientação da coleta dos dados, levantamento dos resultados, análise, interpretação e apresentação.

Foram critérios de inclusão: teses que aplicaram teorias de enfermagem, oriundas de programas de Pós-Graduação em Enfermagem no Brasil, no período de 2011 a 2019. Justifica-se essa delimitação de tempo pela criação do Plano Nacional de Pós-Graduação - PNPG 2011-2020, que tem como um dos desafios expandir em 10 anos a titulação de doutores em enfermagem ${ }^{(8)}$. Os critérios de exclusão foram teses que não estavam disponíveis online.

A busca foi realizada no banco de teses e dissertações da Coordenação e Aperfeiçoamento Pessoal de Nível Superior (CAPES) e na Plataforma Sucupira. Foram utilizados os descritores "Teoria" e "Enfermagem" intercalados pelo operador booleano "AND", que resultou em 2.557 documentos, entre teses e dissertações, foi selecionado o filtro "anos (2011-2019)", "teses", "Área Conhecimento: Enfermagem" e "Área Avaliação: Enfermagem", restando 619 estudos que tiveram seus resumos lidos. Foram aplicados os critérios de inclusão e exclusão, resultando em 364 que passaram por análise detalhada com uso do protocolo em que constam os seguintes itens: número, link, título, plataforma, incluído/excluído e respectivo motivo. Destas 364 teses, estavam 302 depositadas na Plataforma Sucupira e 62 na CAPES. Do total, foram excluídas 296 teses por não utilizarem teorias de enfermagem, destas, 59 teses utilizaram a Teoria das Representações Sociais, 67 utilizaram a Teoria Fundamentada de/em Dados, 126 teses utilizaram outra teoria que não era da área da enfermagem, 14 foram excluídas por não utilizarem nenhuma teoria, 29 teses estavam indisponíveis para acesso e uma tese estava repetida, o que resultou em 68 teses para inclusão na análise.

As teses foram lidas na íntegra para fichamento e extração de aspectos de interesse que alimentaram uma planilha no Microsoft Excel® versão 2019, com as seguintes variáveis: ano de realização, universidade, autor, orientador, programa, teoria, modo de aplicação, tipo de estudo, natureza e temática. Cinco teses foram excluídas após leitura completa por não utilizarem as teorias de enfermagem, apenas as citarem. Ao final, 63 teses formaram o corpus do estudo.

Para a análise dos dados, utilizou-se a estatística descritiva com uso de frequência absoluta e relativa, para calcular os resultados e apresentar os achados, explanados em gráficos.

Reforça-se que esse tipo de estudo não requer a apreciação do Comitê de Ética em Pesquisas com Seres Humanos; no entanto, para uma melhor confiabilidade e rigor dos resultados, a busca foi realizada por pares.

\section{RESULTADOS}

Foram analisadas 63 teses brasileiras distribuídas entre 2011 e 2019, sendo que o 
maior número de produções aconteceu em 2016 com 16 (25,4\%) teses, seguido de 2017 com 12 (19\%), $2015 \mathrm{com}$ nove (14,3\%), $2018 \mathrm{com}$ sete $(11,1 \%), 2013 \mathrm{com}$ sete $(11,1 \%)$, 2014 com cinco (7,9\%), 2012 com quatro (6,3\%), 2011 com duas (3,2\%) e 2019 com uma $(1,6 \%)$.

Quanto às regiões de produção, destacaram-se o Nordeste com $31(49,2 \%)$ e o Sudeste com 27 teses (42,9\%), principalmente nas figuras da Universidade Estadual do Ceará com oito $(12,7 \%)$ do total e a Universidade de São Paulo (USP) com nove $(14,3 \%)$ (Figura 1).

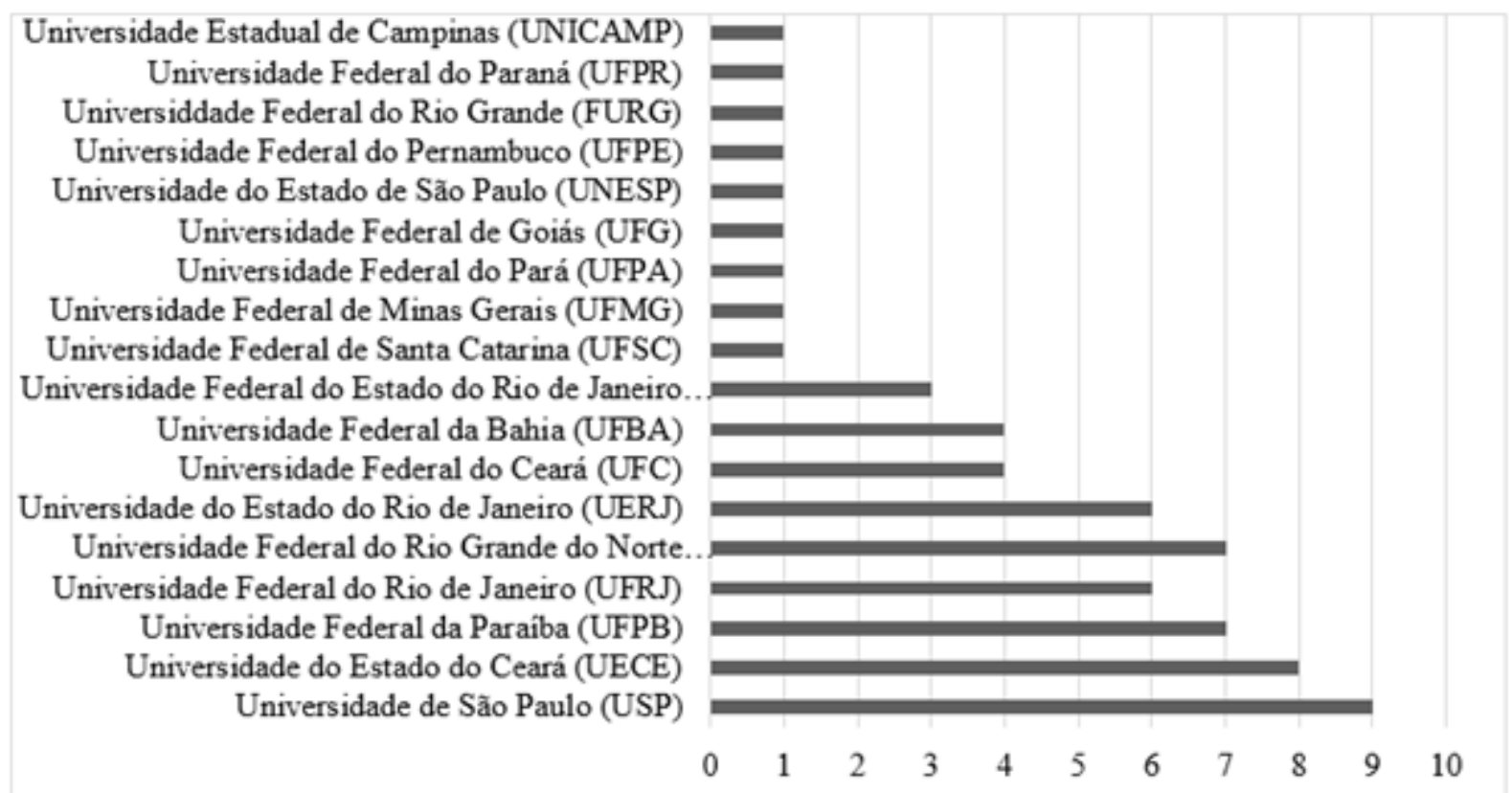

Figura 1 - Distribuição das teses de acordo com a Universidade, entre 2011 e 2019 (n=63). Crato, Ceará, Brasil, 2020

Fonte: Autores (2020)

Conforme análise, $16(25,4 \%)$ trabalhos tiveram orientadores repetidos, com destaque para uma orientadora da UFPB com cinco $(7,9 \%)$ teses orientadas e uma pesquisadora da USP com quatro (6,3\%). Com relação aos programas, 49 (77,8\%) eram de pós-graduação em enfermagem, oito $(12,7 \%)$ pós-graduação em cuidados clínicos em enfermagem e saúde, três $(4,8 \%)$ pós-graduação interunidades em ensino de ciências e três $(4,8 \%)$ pósgraduação em enfermagem na saúde do adulto.

A teoria mais utilizada nas pesquisas foi a Teoria do Cuidado Transcultural de Madelaine Leininger que constou em oito $(12,7 \%)$, seguida da Teoria das Necessidades Humanas Básicas de Wanda Horta e da Teoria de Intervenção Práxica da Enfermagem em Saúde Coletiva, cada uma constando em sete $(11,1 \%)$ teses (Figura 2). 


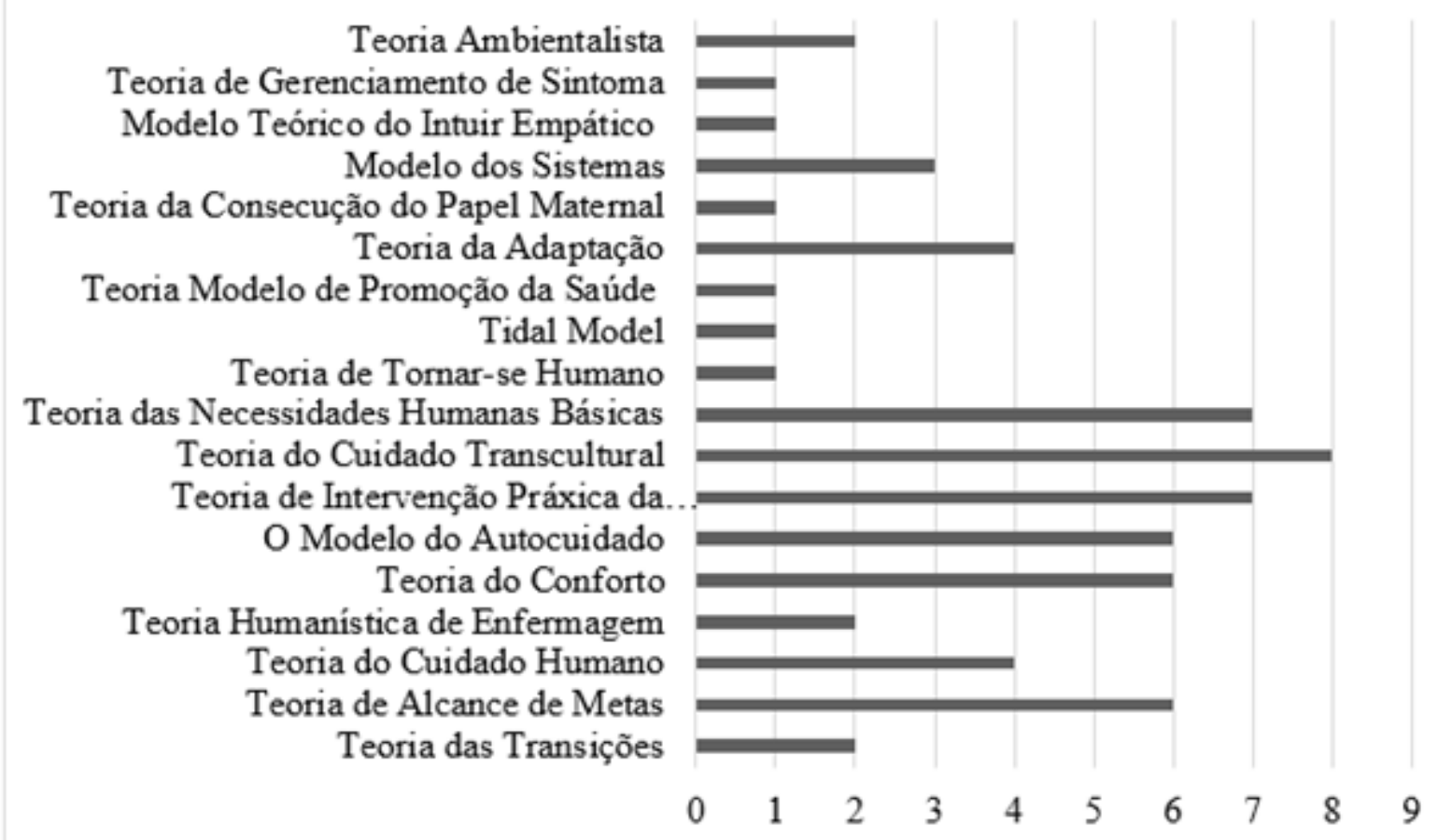

Figura 2 - Distribuição das Teorias de Enfermagem utilizadas nas teses, entre 2011 e 2019 (n=63). Crato, Ceará, Brasil, 2020

Fonte: Autores (2020)

Quanto ao modo de aplicação dessas teorias de enfermagem, encontrou-se um déficit na descrição metodológica dos estudos; grande parte das pesquisas não explanaram de forma direta o modo de uso e, mesmo após a análise desses dados, o modo não ficou nítido. No entanto, das que especificaram, o destaque maior foi dado para a utilização como referencial teórico, em 35 (55,6\%) teses.

A temática prevalente foi o cuidado com 12 (13\%) teses; porém, outros estudos deram um foco maior em outros aspectos, como o cuidar em saúde da criança com 11 (12\%), Classificação Internacional para a Prática de Enfermagem - CIPE® com 10 (10,9\%), saúde da mulher com oito (8,7\%), doenças cardiovasculares em sete $(7,6 \%)$ estudos, seis $(6,5 \%)$ utilizaram o Processo de Enfermagem e cinco $(5,4 \%)$ teses pesquisaram sobre saúde do idoso. Além de outras temáticas como diabetes mellitus, educação, relação interpessoal, consulta e saúde mental, constando em três $(3,3 \%)$ teses respectivamente, e por fim, demais temáticas como a síndrome da imunodeficiência adquirida, tuberculose e hanseníase, doença renal, estomia, instrumentos e estresse, cada uma aparecendo em duas $(2,2 \%)$ teses.

O tipo de estudo mais aplicado foi o metodológico com $24(29,6 \%)$ teses, seguido pelo estudo descritivo com 20 (24,7\%) e o exploratório com 10 (12,3\%). Em relação à natureza, 30 teses $(47,6 \%)$ utilizaram a abordagem qualitativa, sete $(11,1 \%)$ quantitativa e três $(4,8 \%)$ eram estudos mistos.

\section{DISCUSSÃO}

Nesse estudo, o ano de 2016 se sobressaiu com o maior número de produções, oriundas principalmente das regiões Nordeste e Sudeste. Realidade semelhante foi encontrada em um estudo que caracterizou as produções científicas sobre consulta de 
enfermagem nos resumos de teses e dissertações publicadas por enfermeiros no Brasil, entre os anos de 2001 e 2015, que tiveram seus maiores achados nas regiões Sudeste e Nordeste com $80,5 \%$ dos resultados ${ }^{(9)}$.

Esses dados podem ser explicados pela crescente expansão da pós-graduação no Brasil, que gerou um aumento no número de doutores em $64 \%$ entre 2012 e 2016 , alcançando a marca de 1.309 novos doutores. Nessa mesma perspectiva, o Nordeste também obteve crescimento dentre as outras regiões, com o aumento relativo de $61 \%$, entre 2013 e 2016, mesmo com o Sudeste ainda mantendo o maior número de doutores ${ }^{(6)}$.

Ainda sobre a Região Nordeste, identifica-se uma docente da UFPB com a maior quantidade de teses orientadas, que referenciaram as teorias de enfermagem. O Programa de Pós-Graduação em Enfermagem em que essa professora está inserida teve sua ampliação nos últimos anos com mais disponibilidade de cursos, mais linhas de pesquisa e aprofundamento, o que favoreceu um aumento na produção científica e na difusão na literatura nacional e internacional(10).

Esse acontecimento é coerente com o que vem ocorrendo nos demais Programas de Pós-Graduação Stricto Sensu do Brasil, que contribuem para o desenvolvimento do país e avançam com novos cursos de doutorado, voltados para a formação de exímios pesquisadores, que possuam excelência para atuar em suas áreas, no desenvolvimento de competências, no exercício educativo e na geração de novos cientistas ${ }^{(11)}$.

$\mathrm{Na}$ busca dessa excelência e como foco do estudo, as teorias de enfermagem foram os eixos investigados nas teses analisadas, nas quais assumiram principalmente - papel de referenciais teóricos, que conferem visibilidade científica, transcendendo a essência tecnicista da enfermagem, ao oferecer conhecimentos que proporcionam o desenvolvimento da práxis ${ }^{(12)}$.

Além dos referenciais teóricos, a visibilidade científica também ocorre com a estruturação dos aspectos metodológicos utilizados nas teses, sendo que se observou nessa bibliometria que o tipo de estudo mais prevalente foi o metodológico, seguido pelo descritivo e exploratório. Um estudo(13) que analisou o desempenho de 18 doutorados em enfermagem, funcionando no período de 1982 a 2010, apresentou achados similares, tendo os tipos descritivo e descritivo-exploratório os mais utilizados nas teses e o metodológico como o mais aplicado nas produções quantitativas. Quanto ao delineamento da pesquisa, a natureza qualitativa foi a mais encontrada na presente pesquisa, o que pode ser justificado pelo fato de que essa abordagem foi a pioneira em pesquisas na área da saúde ${ }^{(10)}$.

Com esse plano de fundo, as teorias de enfermagem e as formas de aplicação utilizadas foram diversas, mas sempre justificadas pela credibilidade que oferecem aos trabalhos bem embasados. Nessa perspectiva, uma pesquisa qualitativa, realizada com o objetivo de analisar a percepção de pós-graduandos acerca das teorias de enfermagem na formação e na prática profissional, identificou que há carência do seu ensino durante a graduação, necessitando de inserção nos currículos dos cursos. Da mesma forma, sua retomada na pós-graduação foi vista como oportuna, já que o conhecimento a respeito das teorias permite ao profissional ver sua essência, fortalecer a prática cientificamente e reconhecê-las como norteadoras do trabalho ${ }^{(12)}$.

Notou-se que as teorias não são utilizadas de modo uniforme no país e, quando utilizadas, muitas vezes acontece de forma superficial. Porém mesmo com essas ressalvas, identificou-se, nesse estudo, a Teoria do Cuidado Transcultural de Madelaine Leininger como a teoria mais utilizada pelos doutorandos. Ao contrário do que foi encontrado em um estudo que analisou produções entre 1985 e 2012, a fim de identificar decisões e ações do cuidado em enfermagem alicerçadas na Teoria do Cuidado Transcultural, que apontou um número reduzido de publicações ${ }^{(14)}$.

Leininger versa que compreender e utilizar o cuidado cultural, entendendo as diferenças e semelhanças entre as culturas, pode auxiliar no estabelecimento da natureza, 
da essência, dos significados, das expressões e das formas do cuidado humano, conferindo um corpo de conhecimento completamente exclusivo, credível e confiável para a área da enfermagem ${ }^{(15)}$.

Nessa revisão bibliométrica, identificou-se que a teoria de Leininger foi utilizada nos estudos analisados para compreender e implementar ações para populações vulneráveis e culturalmente diversas, tais como quilombolas, ribeirinhas e idosos. Para esses grupos, foram implementadas medidas atreladas ao contexto sociocultural, que oportunizaram a oferta de cuidado inerente ao ser e delinearam orientação para a prática de enfermagem na perspectiva de prover cuidados culturalmente congruentes.

Outra teoria que, além de convergir para esse corpo de conhecimento, veio para embasar a sistematização da prática, foi a Teoria das Necessidades Humanas Básicas de Wanda de Aguiar Horta, a segunda mais utilizada nas teses brasileiras, que tem como essência a implementação, pela equipe de enfermagem, de estados de equilíbrio, prevenção e reversão de desequilíbrios e sua conversão em equilíbrio, na assistência ao indivíduo dentro de suas necessidades básicas, utilizando o método denominado Processo de Enfermagem (PE)(16).

O PE foi um dos temas trabalhados nas teses - trata-se de um instrumento da sistematização da assistência, composto de seis fases, que trouxe inquestionável visibilidade e valorização para a profissão. Mesmo em meio a dificuldades e desafios na sua aplicação, é visto pelos enfermeiros como contribuinte positivo para a qualidade assistencial bem como para o reconhecimento do seu trabalho(17).

Atingindo a mesma quantidade de utilização da Teoria de Horta, outra teoria que também consiste na assistência de enfermagem, sendo mais voltada para um determinado campo de atuação, é a Teoria de Intervenção Práxica da Enfermagem em Saúde Coletiva (TIPESC), da Emiko Yoshikawa Egry. Ela está assentada na visão materialista histórica e dialética, e busca intervir por meio de uma metodologia dinâmica, dialética e participativa, compreendendo contradições do campo teórico e de práticas, a realidade objetiva da Enfermagem em Saúde Coletiva ${ }^{(18)}$.

Após duas décadas de utilização, a TIPESC consolidou-se dentro de disciplinas da graduação e pós-graduação da Universidade de São Paulo; as experiências permitiram testes das vertentes teóricas, metodológicas, instrumentais, políticas e pedagógicas da teoria. Inclusive, por meio da pós-graduação, foi possível a participação de profissionais de outras áreas da saúde, o que tem enriquecido o potencial de aplicação da TIPESC ${ }^{(19)}$.

Percebe-se, então, que as teorias da enfermagem também podem ser utilizadas por profissionais não enfermeiros, assim como enfermeiros utilizam teorias de outras áreas, como suporte teórico e metodológico para suas pesquisas. Como exemplo, a Teoria das Representações Sociais e a Teoria da Fundamentação de Dados encontradas em produções excluídas desse estudo.

Reforça-se que a utilização das teorias de enfermagem pelos enfermeiros fornece a compreensão da enfermagem como ciência e contribui para o válido reconhecimento que a profissão merece ${ }^{(20)}$.

Em consonância com a discussão do reconhecimento e crescimento da enfermagem enquanto ciência, observa-se ainda desafios no tocante à formação de recursos humanos, no despreparo metodológico dos pesquisadores, nas suas produções científicas e na transformação da sociedade por meio da difusão do conhecimento ${ }^{(11)}$. Realidade que pode explicar o porquê de as teorias serem utilizadas superficialmente ou não serem utilizadas, já que é necessário conhecimento acurado acerca da teoria e seu uso.

É perceptível que já no curso de graduação em enfermagem há um distanciamento entre $\circ$ processo de formação e o apreendimento e internalização das teorias de enfermagem como suporte teórico para a prática, sendo que a inserção desse conteúdo 
deveria permear horizontalmente a matriz curricular e servir de subsídio para a práxis dos futuros enfermeiros ${ }^{(21)}$.

Referente às questões estudadas, pesquisadores enfermeiros evidenciam como relevante o desenvolvimento de estudos sobre a temática do cuidado de enfermagem, pois ele é definido como o objeto que caracteriza e dá identidade à profissão. $O$ cuidado precisa ser transfixado na prática clínica e nos registros dos enfermeiros, sendo embasado e atualizado em termos de produções científicas ${ }^{(22)}$. Nota-se, então, nas teses analisadas nesse estudo, o cuidado como a temática mais investigada pelos enfermeiros, sendo eles o cuidado empregado nos ambientes familiar e o domiciliar.

Observa-se a necessidade do uso de teorias de enfermagem aplicadas ao cuidado na prática, de modo a transcender e impactar de forma direta, a assistência prestada à sociedade e difundir o conhecimento produzido e consubstanciado pelo próprio enfermeiro.

Como limitações, temos a indisponibilidade de algumas teses, pois muitos autores, programas e universidades não permitem a divulgação, o que impossibilita a análise de um quantitativo maior dos estudos que utilizaram as teorias de enfermagem. Há também uma lacuna na literatura no que se refere à reflexão sobre o uso das teorias de modo geral, pois se encontra materiais mais direcionados às teorias e temáticas específicas e pouco sobre todo o corpo de conhecimento que constitui a enfermagem ciência. No entanto, esse estudo bibliométrico apresenta-se como uma importante análise, pois essa visão geral sobre a utilização das teorias de enfermagem oferta à área o progresso que ela já teve ao longo dos anos e abre caminhos para reflexões sobre aonde ela quer chegar, tanto na construção como na aplicação do conhecimento próprio.

\section{CONCLUSÃO}

É grande a quantidade de teorias de enfermagem em teses, as temáticas que podem ser trabalhadas e suas formas de aplicação, tanto na pesquisa como na prática clínica dos enfermeiros. A inclusão dessas teorias no ensino da enfermagem e a maneira de utilizá-las na pesquisa e na práxis do enfermeiro ainda se mantêm intrincadas; nos achados dessa caracterização, muitos autores limitaram a aplicação das teorias apenas como marcos teóricos. Em algumas teses, a aplicação dessas só era identificada em seções especiais, não sendo detectada no corpo do estudo.

Nesta lógica, a pós-graduação pode ser vista como uma oportunidade para os enfermeiros pesquisadores terem maior aproximação e apropriação dessas teorias, utilizando-as de modo a contribuir para o crescimento da enfermagem enquanto profissão e ciência, inclusive em seus estudos metodológicos, dando origem a mais conhecimentos e materiais que se se aproximem tanto do abstrato como do prático.

Com esse estudo, pretende-se dar visibilidade à temática e sugerir que as instituições aprofundem a discussão sobre as teorias de enfermagem nas graduações e pós-graduações, para que os alunos possam adquirir proximidade e domínio daquilo que fundamenta seu conhecimento teórico e prático.

\section{AGRADECIMENTOS}

Agradecimentos à Fundação Cearense de Apoio ao Desenvolvimento Científico e 
Tecnológico - FUNCAP pelas bolsas concedidas às autoras, sob os números BMD-00080151701 14/19 e BMD-000801517 01 13/19, no edital de Programa de Bolsas de Formação Acadêmica - Modalidade: Mestrado e Doutorado, número 05/2019, que oportunizaram a realização desta pesquisa.

\section{REFERÊNCIAS}

1. Teodosio SSC, Padilha MI. "Ser enfermeiro": escolha profissional e a construção dos processos identitários (anos 1970). Rev bras enferm. [Internet]. 2016 [acesso em 29 nov 2019]; 69(3). Disponível em: http://dx.doi.org/10.1590/0034-7167.2016690303i.

2. Dias JAA, David HMSL, Vargens OM da C. Ciência, enfermagem e pensamento crítico - reflexões epistemológicas. Rev enferm UFPE on line. [Internet]. 2016 [acesso em 16 maio 2020]; 10(supl4). Disponível em: https://periodicos.ufpe.br/revistas/revistaenfermagem/article/view/11142/12645.

3. Pires $A F$, Santos $B N$ dos, Santos $P N$ dos, Brasil VR, Luna AA. A importância da teoria de do autocuidado de Dorothea E. Orem no cuidado de enfermagem. Rev. Rede Cuid. Saúde. [Internet]. 2015 [acesso em 28 nov 2019]; 9(2). Disponível em: http://publicacoes.unigranrio.edu.br/index.php/rcs/article/ view/2533.

4. Bousso RS, Poles K, Cruz D de ALM da. Nursing concepts and theories. Rev esc enferm USP. [Internet]. 2014 [acesso em 28 nov 2019]; 48(1). Disponível em: http://dx.doi.org/10.1590/S0080$\underline{623420140000100018 .}$

5. Brito LSA de, Sousa NDL de, Alencar AMPG, Rebouças VCF, Pinheiro PP, Gonçalves Júnior J. Concepts, theoretical models and nursing theories: integrative review. Int Arch Med [Internet]. 2017 [acesso em 29 nov 2019]; 10(166). Disponível em: https://www.researchgate.net/publication/317273969 Concepts theoretical models and nursing theories integrative review.

6. Ministério da Educação (BR). Coordenação de Aperfeiçoamento de Pessoal de Nível Superior (CAPES). Relatório de Avaliação 2013-2016: enfermagem. [Internet]. Brasília: CAPES; 2017 [acesso em 10 nov 2019]. Disponível em: https://www.capes.gov.br/images/stories/download/avaliacao/relatorios-finaisquadrienal-2017/20122017-ENFERMAGEM-quadrienal.pdf.

7. Araújo CAA. Bibliometria: evolução histórica e questões atuais. Em Questão. [Internet]. 2006 [acesso em 10 nov 2019]; 12(1). Disponível em: https://seer.ufrgs.br/EmQuestao/article/view/16.

8. Ministério da Educação (BR). Coordenação de Aperfeiçoamento de Pessoal de Nível Superior (CAPES). Plano Nacional de Pós-Graduação - PNPG 2011-2020. [Internet]. Brasília: CAPES; 2010 [acesso em 11 nov 2019]. Disponível em: https://www.capes.gov.br/images/stories/download/PNPG Miolo V2.pdf.

9. Menezes HF de, Rosas AMMTF, Souza FS de, Viana L de O, Pinto ACS, Rufino CG. Produção brasileira de teses e dissertações sobre consulta de enfermagem: estudo de natureza bibliométrica. Rev. Enf. Atual [Internet]. 2019 [acesso em 03 dez 2019]; 83. Disponível em: https://revistaenfermagematual.com/index. php/revista/article/view/290/181.

10. Pimenta CJL, Fernandes WAA de B, Falcão RM de M, Freitas S de A, Oliveira J dos S, Costa KN de FM. Análise das dissertações e teses do programa de pós-graduação em Enfermagem da Universidade Federal da Paraíba. REME [Internet]. 2018 [acesso em 07 dez 2019]; 22(e1093). Disponível em: http:// www.dx.doi.org/10.5935/1415-2762.20180023.

11. Silva RS da. Postgrado e investigación en enfermería en américa latina: avances y desafíos. Rev Cuid. [Internet]. 2015 [acesso em 19 maio 2020]; 6(2). Disponível em: http://dx.doi.org/10.15649/cuidarte. v6i2.307.

12. Merino M de FGL, Silva PL de AR da, Carvalho MD de B de, Pelloso SM, Baldissera VDA, 
Higarashi IH. Nursing theories in professional training and pratice: perception of postgraduate nursing students. Rev Rene [Internet]. 2018 [acesso em 10 jan 2019]; 19(e3363). Disponível em: http://dx.doi. org/10.15253/2175-6783.2018193363.

13. Scochi CGS, Gelbcke FL, Ferreira M de A, Lima MAD da S, Padilha KG, Padovani NA, Munari DB. Nursing Doctorates in Brazil: research formation and theses production. Rev. Latino-Am. Enfermagem. [Internet]. 2015 [acesso em 19 mai 2020]; 23(3). Disponível em: https://www.scielo.br/scielo. php?pid=S0104-11692015000300387\&script=sci arttext.

14. Betiolli SE, Neu DK de M, Meier MJ, Wall ML, Lenardt MH. Decisões e ações de cuidados em enfermagem alicerçadas em Madeleine Leininger. Cogitare enferm [Internet]. 2013 [acesso em 12 jan 2019]; 18(4). Disponível em: https://revistas.ufpr.br/cogitare/article/view/34936/21688.

15. Leininger MM. Transcultural nursing concepts, theories e practices. Columbus, OH: McGraw-Hill Custom Series, 1995.

16. Horta WA. Enfermagem: teoria, conceitos, princípios e processo. Rev. esc. enferm. USP [Internet]. 1974 [acesso em 03 set 2020]; 8(1). Disponível em: https://www.scielo.br/pdf/reeusp/v8n1/0080-6234reeusp-8-1-007.pdf.

17. Benedeti SA, Gelbcke FL, Amante LN, Padilha MIC de S, Pires DEP de. Processo de Enfermagem: instrumento da sistematização da assistência de enfermagem na percepção dos enfermeiros. Rev. Pesqui. Cuid. Fundam. (Online) [Internet]. 2016 [acesso em 15 jan 2019]; 8(3). Disponível em: https://dialnet. unirioja.es/servlet/articulo?codigo $=5618248$.

18. Egry EY. Saúde Coletiva: construindo um novo método em enfermagem. São Paulo: Ícone; 1996.

19. Egryl EY, Fonseca RMGS da, Oliveira MA de C, Bertolozzi MR. Nursing in Collective Health: reinterpretation of objective reality by the praxis action. Rev bras enferm [Internet]. 2018 [acesso em 17 jan 2019]; 71(1). Disponível em: https://doi.org/10.1590/0034-7167-2017-0677.

20. Ramalho Neto JM, Marques DKA, Fernandes M das GM, Nóbrega MML da. Meleis' Nursing Theories Evaluation: integrative review. Rev bras enferm. [Internet]. 2016 [acesso em 15 dez 2019]; 69(1). Disponível em: http://dx.doi.org/10.1590/0034-7167.2016690123i.

21. Santos BP, Sá FM de, Pessan JE, Criveralo LR, Bergamo LN, Gimenez VC de A, Fontes CMB, Plantier GM. Formação e práxis do enfermeiro à luz das teorias de enfermagem. Rev bras enferm [Internet]. 2019 [acesso 17 mai 2020]; 72(2). Disponível em: http://dx.doi.org/10.1590/0034-7167-2018-0394.

22. Lino MM, Backes VMS, Costa MA da SMC da, Martins MMFP da S, Lino MM. Research in nurning: Brazil and Portugal in the construction of professional identity. Texto contexto-enferm. [Internet]. 2018 [acesso em 08 jan 2020]; 27(1). Disponível em: http://dx.doi.org/10.1590/0104-07072018006550015. 


\section{COMO REFERENCIAR ESTE ARTIGO:}

Alves HLC, Lima G de S, Albuquerque GA, Gomes EB, Cavalcante EGR, Amaral MCV. Uso das teorias de enfermagem nas teses brasileiras: estudo bibliométrico. Cogitare enferm. [Internet]. 2021 [acesso em "colocar data de acesso, dia, mês abreviado e ano"]; 26. Disponível em: http://dx.doi.org/10.5380/ce.v26i0.71743.

Recebido em: 14/02/2020

Aprovado em: 23/07/2020

Editora associada: Susanne Elero Betiolli

Autor Correspondente:

Héryka Laura Calú Alves

Universidade Regional do Cariri - Crato, CE, Brasil

E-mail: herykalaura_@hotmail.com

\section{Contribuição dos autores:}

Contribuições substanciais para a concepção ou desenho do estudo; ou a aquisição, análise ou interpretação de dados do estudo - HLCA, GSL

Elaboração e revisão crítica do conteúdo intelectual do estudo - GAA, EBG

Aprovação da versão final do estudo a ser publicado - EGRC, MCVA

Copyright () 2021 Este é um artigo em acesso aberto distribuído nos termos da Licença Creative Commons Atribuição, que permite o uso irrestrito, a distribuição e reprodução em qualquer meio desde que o artigo original seja devidamente citado. 